\title{
A switch in translation mediated by an antisense RNA
}

\author{
Koustubh Ranade and Anthony R. Poteete ${ }^{1}$ \\ Department of Molecular Genetics and Microbiology and Program in Molecular Medicine University of Massachusetts, \\ Worcester, Massachusetts 01655 USA
}

\begin{abstract}
Antisense RNAs regulate expression of target genes in a variety of ways-transcription termination, translation initiation, and mRNA stability. We describe a case in which the target gene encodes two polypeptides, and antisense RNA causes a switch in its translation by selectively inhibiting synthesis of one of the polypeptides. Bacteriophage P22 is a temperate Salmonella phage; in the prophage state it expresses only a handful of its genes. One of these genes, sieB, aborts the lytic development of some phages. P22 itself is insensitive to the lethal effect of SieB because it harbors a determinant called esc. We show that the sieB gene encodes two polypeptides-SieB, which is the exclusion protein, and Esc, which is a truncated version of SieB that inhibits its action. Superinfecting P22 synthesizes an antisense RNA, sas, that inhibits synthesis of SieB but allows continued synthesis of Esc, thus allowing P22 to bypass SieB-mediated exclusion. This translational switch induced by sas RNA is essential to vegetatively developing P22; a mutation that prevents this switch causes P22 to commit SieB-mediated suicide. Finally, we show that P22's Esc allows it to circumvent the SieB-mediated exclusion system of bacteriophage $\lambda$.
\end{abstract}

[Key Words: Superinfection exclusion; antisense RNA; translational switch]

Received April 26, 1993; revised version accepted June 7, 1993.

In prokaryotes, antisense RNAs have been shown to regulate gene expression in a variety of ways. In some cases, antisense RNAs regulate expression of the target gene by base-pairing with its ribosome-binding site and preventing translation initiation; in other cases, they have been shown to cause premature transcription termination by hybridizing with the target RNA and forming a structure that mimics a transcription terminator. In another case, the antisense RNA has been shown to destabilize the target mRNA by creating a site for RNase III cleavage (for reviews, see Simons and Kleckner 1988; Takayama and Inouye 1990). On this theme of regulation by antisense RNA, we present a variation. We describe a case in which the target gene encodes two polypeptides, and the antisense effector RNA causes a switch in phenotype by selectively inhibiting synthesis of one of them.

Bacteriophage P22 is a temperate Salmonella phage that closely resembles coliphage $\lambda$ in its genetic structure and the regulation of expression of its genes (for a review of P22 biology, see Poteete 1988). Like other temperate phages, P22 expresses only a handful of its genes in the prophage state; their function, at least in part, is to prevent the growth of superinfecting phages. One of these genes, sieB, aborts the lytic development of some superinfecting phages (Susskind et al. 1974). In a SieB ${ }^{+}$ host, vegetative development of sensitive phages proceeds normally for $\sim 20 \mathrm{~min}$, but then there is an abrupt

${ }^{1}$ Corresponding author. cessation of all-phage and host-macromolecular synthesis; as a result, release of progeny phage is prevented and the host cell dies. Susskind and co-workers showed that P22 itself is not susceptible to SieB-mediated exclusion because it harbors a determinant esc (for escape from SieB-mediated exclusion); they showed further that this P22 function can act in trans and is negatively regulated by the prophage repressor acting at the major leftward promoter of P22 (see Fig. 1). Below, we present the likely molecular mechanism that P22 utilizes to escape SieBmediated exclusion.

In a previous study we identified the $s i e B$ gene and its promoter (Ranade and Poteete 1993). The sieB gene, which encodes a polypeptide of 192 amino acid residues, is embedded in the $p_{\mathrm{L}}$ operon; unlike other genes in this operon, which are read leftward and repressed in the prophage state, $s i e B$ is read rightward and expressed in a lysogen. We now show that the $\operatorname{sie} B$ gene encodes another polypeptide (referred to as Esc), which is an inhibitor of the exclusion protein SieB. The inhibitor, Esc, is a truncated version of SieB itself; it lacks the aminoterminal 25 amino acid residues and is synthesized from an internal initiation codon in sieB. We present genetic evidence to show that superinfecting P22 synthesizes an antisense RNA that causes ribosomes to switch from synthesizing both the exclusion and inhibitor proteins (SieB and Esc, respectively) to synthesizing only Esc, thereby allowing P22 to escape SieB-mediated exclusion. There is redundancy in the system because 
functional amounts of Esc can be made either by the prophage or the superinfecting phage. We show further that in the presence of SieB, this switch in translation is essential for the lytic development of P22; a mutation that likely prevents this switch is lethal to vegetatively growing P22. Finally, we present evidence indicating that P22's Esc can disarm the sieB exclusion system of bacteriophage $\lambda$.

\section{Results}

\section{esc as antisense RNA}

Preliminary experiments designed to detect post-transcriptional regulation of the major leftward operon $\left(p_{\mathrm{L}}\right)$ of bacteriophage $\mathrm{P} 22$ revealed that the $p_{\mathrm{L}}$ transcript is processed in the vicinity of the $\operatorname{sie} B$ gene. This processing was investigated further using an RNase protection assay, and the results are presented in Figure 1.

Wild-type Salmonella was infected with virulent P22, and RNA was isolated 10, 20, and 30 min after infection. The riboprobes used in the experiment are shown in Figure $1 \mathrm{~A}_{\text {; }}$ two of the riboprobes (Hpa and Nde) have a common $5^{\prime}$ end that is 75 bp upstream of the transcription start site of sieB/esc. They have different 3 ' ends; the Hpa probe extends to the HpaI site and has $\sim 426$ nucleotides of complementarity with the $p_{\mathrm{L}}$ transcript. The
Nde probe has $\sim 175$ nucleotides of complementarity and extends to the NdeI site in sieB/esc. The third probe (Xmn) has a different $5^{\prime}$ end; it extends from the HindIII site in ral for 426 nucleotides to the XmnI site in sieB/ esc. As can be seen in Figure 1B, the Hpa probe is fully protected by RNA extracted 10 min postinfection /where observed, the difference in size between the fully protected and the untreated probes is the result of the presence of vector sequences in the probe); between 10 and 20 min after infection, however, there is a decrease in the full-length probe with a concomitant increase in a 105nucleotide protected fragment. This pattern is mirrored in the experiment with the Nde probe, suggesting that the $5^{\prime}$ end of the 105-nucleotide fragment is to the left of the NdeI site. A 105-nucleotide protected riboprobe is obtained even when one uses a probe with a different 5' end (Xmn probe). Taken together, these results indicate that the $p_{\mathrm{L}}$ transcript (in this region) is processed into a 105-nucleotide RNA species, and this processed fragment lies within the boundaries of the Nde probe. In addition to the 105-nucleotide fragment, the Xmn probe yields three other protected species. The largest of these is the full-length probe. We suspect that the other two (280 and 300 in Fig. 1B) are partially processed forms of the $p_{\mathrm{L}}$ transcript; their likely provenance is diagramed in Figure 1A. These two partially processed RNAs also allow one to identify the most likely ends of the 105-nu-

A

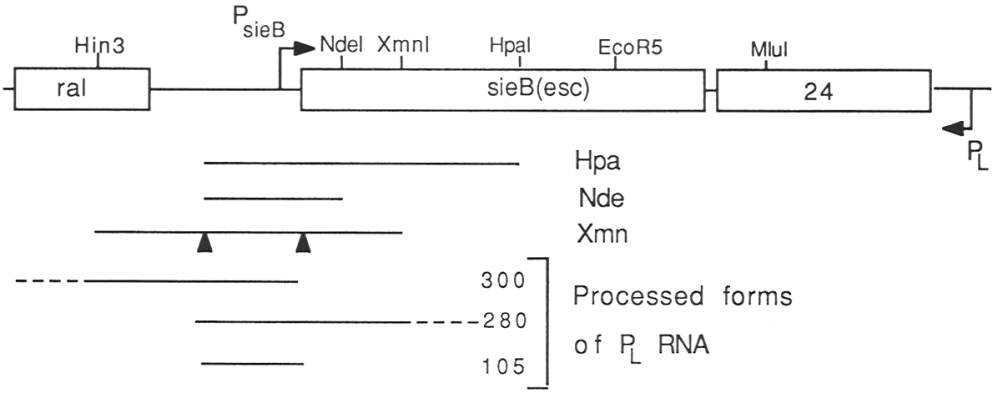

B

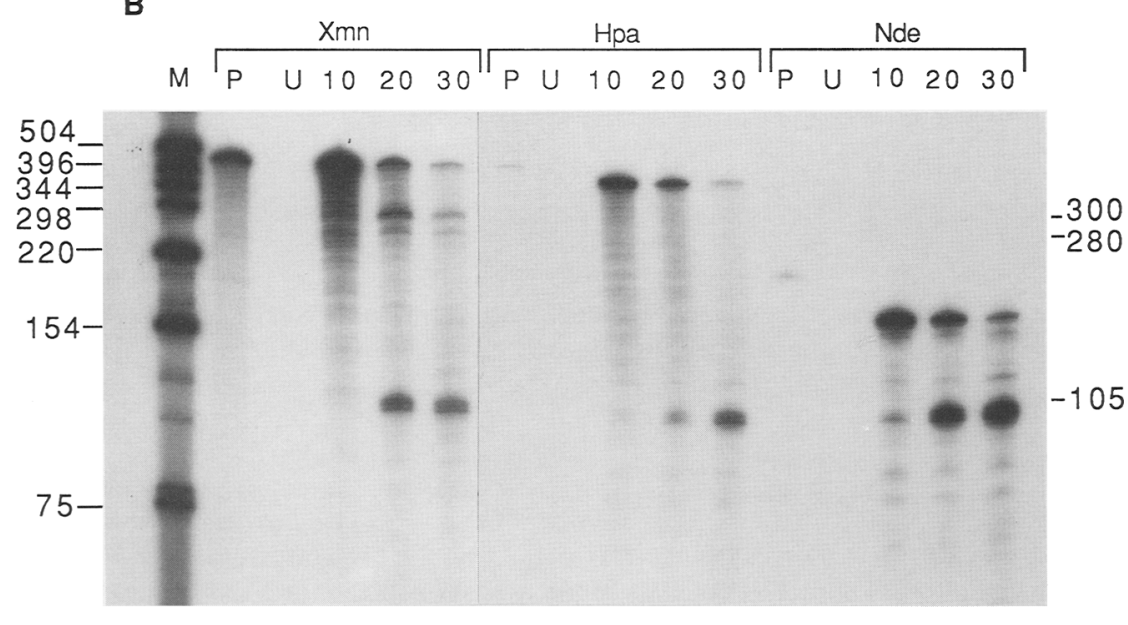

Figure 1. RNase protection experiment to detect sas RNA. (A) The riboprobes used in the experiment are indicated as solid lines. Arrowheads under the Xmn probe indicate the likely processing sites in the $p_{\mathrm{L}}$ transcript. (300 and 280) The singly processed forms of $p_{\mathrm{L}}$ RNA and (105) the antisense effector RNA, sas; the numbers refer to the number of nucleotides in each species, inferred from the gel shown in $B$. Broken lines indicate that the RNA species is longer than that detected by the Xmn probe. $(B)$ Autoradiograph of a $6 \%$ polyacrylamide $/ 8 \mathrm{M}$ urea gel used to separate riboprobes protected from nucleases by RNA extracted from phage-infected cells. Xmn, Hpa, and Nde refer to the three riboprobes shown in $A$. (P) Untreated riboprobe; (U) RNA extracted from uninfected cells. The numbers 10,20 , and 30 indicate that RNA was extracted 10,20 , and 30 min after phage infection. The 300-, 280-, and 105-nucleotide fragments discussed in the text are marked at right. Markers (M) are Hinfl fragments of pBR322, filled in by the Klenow fragment of $E$. coli DNA polymerase $I$ in the presence of $\left[\alpha{ }^{32} \mathrm{P}\right] \mathrm{dATP}$. The numbers at left indicate the length of each fragment (in nucleotides). 
Table 1. Esc phenotypes of P22 bearing different alleles of sieB/esc on cells expressing different alleles of sieB

\begin{tabular}{lccc}
\hline \multirow{2}{*}{$\begin{array}{l}\text { sieB/esc allele } \\
\text { in P22 }\end{array}$} & \multicolumn{4}{c}{ sieB allele in host ${ }^{\mathrm{a}}$} \\
\cline { 2 - 4 } wild type & substitution 2 & aml15 \\
\hline Wild type & + & + & + \\
Substitution 1 & + & + & + \\
am4 & + & + & + \\
am14 & + & + & + \\
am22 & + & + & + \\
am29 & + & - & + \\
am115 & + & - & + \\
P $_{\text {sieB-10 }}$ & + & - & + \\
Substitution 1 am115 & - & - & + \\
Substitution 2 am115 & - & - & + \\
\hline
\end{tabular}

Salmonella strain MS1868 was transformed with plasmid pKR682 bearing the wild-type allele of $\operatorname{sie} B$, or with derivatives of pKR682 bearing the substitution 2 or am 115 alleles of sieB. Plasmid-bearing cells were grown to late log phase in LB + ampicillin, and $0.1 \mathrm{ml}$ of culture was used to make lawns on LB-ampicillin plates. Tenfold serial dilutions of P22vir3 bearing the indicated alleles of sieB/esc were spotted on such lawns, and the plates were incubated overnight at $30^{\circ} \mathrm{C}$.

${ }^{a}$ A minus sign indicates that the phage plates 100 - to 1000 -fold less efficiently on a particular host as compared with its plating efficiency on Salmonella expressing the am115 allele of sieB/ esc; a plus sign indicates that the plating efficiency is $\sim 1$.

cleotide fragment: The $5^{\prime}$ end of this RNA is at or very near the $\operatorname{sie} B$ initiation codon, and the $3^{\prime}$ end is $\sim 70$ nucleotides to the left of the $s i e B / e s c$ transcription initiation site. This processed fragment of the $p_{\mathrm{L}}$ transcript is referred to, from now on, as sas (sieB antisense) RNA.

Studies by Susskind and co-workers (1974) showed that esc-the determinant in P22 that allows it to bypass SieB-mediated exclusion-is part of the $p_{\mathrm{L}}$ operon and is tightly linked to $s i e B$. Our deletion mapping studies revealed that a critical esc determinant maps almost precisely to the region encompassed by sas RNA (data not shown). Taken together, these observations suggest that esc is sas RNA. Given the small size of this RNA and the fact that it has the potential to base-pair with the ribosome-binding site of $s i e B$, it seemed plausible that sas RNA might be involved in negatively regulating $\operatorname{sie} B$ expression. If $\operatorname{sie} B$ antisense RNA, synthesized by superinfecting P22, acting on the untranslated region of $s i e B$ mRNA, were responsible for allowing P22 to grow in a $\mathrm{SieB}^{+}$cell, one might expect that mutations in the antisense effector that abolish base-pairing with the target sieB mRNA would render P22 susceptible to SieB-mediated exclusion. To test this possibility, a large deletion/ substitution was introduced in the untranslated region of $\operatorname{sie} B$. This mutation-substitution 1 (substitution 1 in Fig. 3B, below)-replaces almost the entire untranslated region of sieB mRNA (24 of 31 nucleotides). The substitution was crossed into virulent P22, and its Esc phenotype was tested. As indicated in Table 1, substitution 1-bearing P22 had no phenotype; P22 sub1 plates as well as does wild-type P22 on cells expressing wild-type sieB. This result, prima facie, would rule out base-pairing be- tween sas RNA and the untranslated region of mRNA as a necessary part of the mechanism by which P22 bypasses SieB-mediated exclusion. As is shown below, however, this result reflects redundancy in the devices that P22 elaborates to circumvent SieB-mediated exclusion-knocking out the antisense effector reveals the action of the inhibitor Esc.

\section{esc as protein}

When expression of proteins was analyzed, using maxicells from the $s i e B$ region of $P 22$, we discovered that two proteins are expressed from this region (see Fig. 2B, lane 3). On the basis of the phenotype of an amber mutation (am4 in Fig. 2A), we inferred that the larger polypeptide is expressed from the $s i e B$ gene (Ranade and Poteete 1993). An examination of the sequence of the $s i e B$ gene revealed four in-frame initiation codons downstream of the sieB initiation codon (indicated as 2, 3, Esc ATG, and 5 in Fig. 2A). To test the possbility that the smaller polypeptide is the result of initiation at one of these ATGs, amber mutations were introduced between consecutive ATGs; an amber mutation was introduced

A

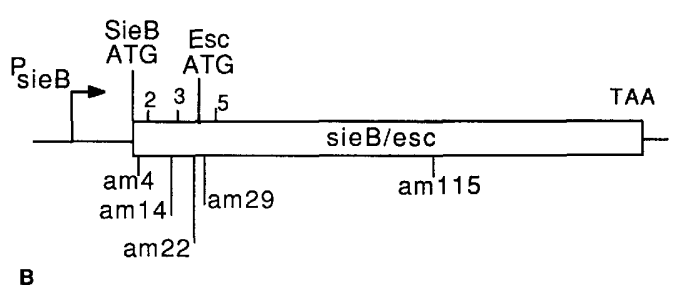

B

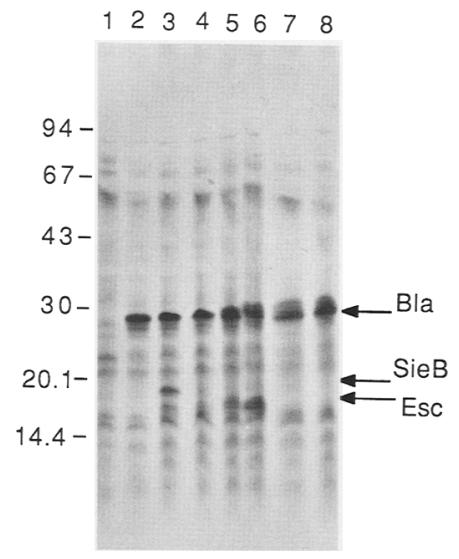

Figure 2. (A) The sieB/esc gene is shown with the amber mutations (am) discussed in the text. The deduced initiation codons of sieB and esc are indicated as SieB ATG and Esc ATG, respectively. $(B)$ Autoradiograph of ${ }^{35} \mathrm{~S}$-labeled proteins expressed in maxicells and separated by SDS-PAGE $(10 \%)$ (tricine system; Schagger and Jagow 1987). (Lane 1) No plasmid; (lane 2) pBR322 with its tetracycline resistance-conferring gene deleted. Lanes 3-7 are derivatives of pKR682 expressing different alleles of sieB/esc. (Lane 3) Wild type; (lane 4) am4; (lane 5) am 14; (lane 6) am22; (lane 7) am29. (Lane 8) am115. Arrows indicate positions of $\beta$-lactamase, SieB, and Esc. The numbers at left indicate molecular mass markers (Pharmacia) (in kilodaltons). 
toward the carboxyl terminus of $\operatorname{sie} B$ as well. Derivatives of pKR682 bearing these amber alleles were constructed, and expression of proteins from these plasmids was analyzed using maxicells. (Plasmid pKR682 is a derivative of pBR322 bearing the HindIII-MluI ral-sieB region of P22; see Fig. 1.) All five amber mutations confer a SieB ${ }^{-}$phenotype (data not shown) and, as shown in Figure $2 \mathrm{C}$, prevent synthesis of the larger, SieB, polypeptide. Only am 29 and am 115 prevent synthesis of the smaller, Esc, polypeptide; am 14 and am22, on the other hand, result in slight overproduction of Esc, perhaps as a result of translation reinitiation by ribosomes terminating at these ambers. Two conclusions can be drawn from these results: First, $\mathrm{SieB}$ and the smaller polypeptide (Esc) are synthesized from the same open reading frame; and second, Esc is initiated, most likely, from the fourth ATG in the $\operatorname{sie} B$ gene.

By analogy with other systems where a truncated protein inhibits the function of the full-length polypeptide [e.g., p1 and p2 proteins of transposon Tn5 (Isberg et al. 1982; Johnson et al. 1982) $\mathrm{S}_{107}$ and $\mathrm{S}_{105}$ proteins of bacteriophage $\lambda$ (Young 1992)], we guessed that Esc may be an inhibitor of SieB-mediated exclusion. When a plasmid expressing the am 22 allele of $\operatorname{sie} B$, which abolishes synthesis of SieB but not Esc, was introduced into a $\mathrm{SieB}^{+}$ lysogen, it converted the cell to a $\mathrm{SieB}^{-}$phenotype /data not shown). We interpreted this result to mean that Esc expressed from the plasmid inhibited the action of endogenous full-length SieB. If Esc were responsible for neutralizing endogenous SieB in a P22-superinfected cell, one would predict that superinfecting P22 bearing amber mutations in $s i e B$ upstream of the esc initiation codon (am4, am 14, and am22; see Fig. 2A) would be able to bypass SieB-mediated exclusion. P22 bearing amber mutations within sequences encoding both sieB and esc (am29 and am115), however, would be sensitive to SieB. To test this prediction, all five amber mutations were crossed into virulent P22, and the ability of P22 bearing these amber mutations to grow on a host expressing wild-type $\operatorname{sie} B$ was tested. As shown in Table 1, not one of the amber mutations has an effect on P22's ability to grow on a SieB ${ }^{+}$cell; P22 strains bearing amber mutations that prevent synthesis of the inhibitor Esc-am29 and am115-plate with the same high efficiency as do P22 strains with amber mutations that do not diminish synthesis of Esc-am4, am14, and am22. These results would appear to rule out a role for Esc in P22's ability to bypass SieB-mediated exclusion. However, as pointed out earlier, this reflects redundancy in the devices that P22 uses to circumvent SieB-mediated exclusion; knocking out the inhbitor, Esc, reveals the action of $s i e B$ antisense RNA.

Superinfecting P22 requires sieB antisense RNA or Esc protein to circumvent SieB-mediated exclusion

Because mutations that would (1) prevent $\operatorname{sie} B$ antisense RNA from interacting with its sense partner (substitution 1), or (2) prevent synthesis of the SieB inhibitor, Esc (sieB/esc am29 and am115), were found not to confer an
Esc ${ }^{-}$phenotype, it seemed possible that superinfecting P22 requires either a function encoded by the $p_{\mathrm{L}}$ operon ( bypass SieB-mediated exclusion. To test this possibility, a P22 strain bearing substitution 1 in combination with the sieB/escam 115 allele was constructed, and its ability to grow on a $\mathrm{SieB}^{+}$host was tested. The results are presented in Table 1. As can be seen, P22 sub1 sieB/escam 115 plates inefficiently on cells expressing wild-type sieB. Neither mutation alone has any effect on the plating behavior of $\mathrm{P} 22$. On the control $\mathrm{SieB}^{-}$host (expressing the sieB/escam115 allele), however, the sub1 sieB/ escam115 double mutant and wild-type P22 plate with the same high efficiency. These results strongly indicate that a P22 strain unable to synthesize its own Esc relies on $\operatorname{sie} B$ antisense RNA to bypass SieB-mediated exclusion.

In the experiment described above, the antisense effector of the infecting phage was wrecked by mutation, thus revealing the role of Esc. We reasoned that the converse experiment should also yield the same result, that is, destroying, by mutation, the ability of the endogenous target $s i e B$ mRNA to interact with the wild-type antisense effector should reveal superinfecting P22's dependence on Esc for bypassing SieB-mediated exclusion. We could not use substitution 1 to test this because it confers a $\mathrm{SieB}^{-}$phenotype (data not shown). Consequently, another mutation was introduced in the untranslated region of $s i e B$. This mutation-substitution 2 in Figure 3B-replaces 9 nucleotides $(2-11)$ in the sieBuntranslated region with unrelated sequence. A derivative of pKR682 was constructed carrying this mutation, and the SieB phenotype of cells bearing this derivative was tested. Salmonella expressing $s u b 2 \operatorname{sieB}$ is phenotypically $\mathrm{SieB}^{+}$; it excludes an $\mathrm{Esc}^{-}$phage but not wildtype P22 (Table 1; data not shown). The plating behavior of P22 bearing various amber alleles of sieB/esc was

A

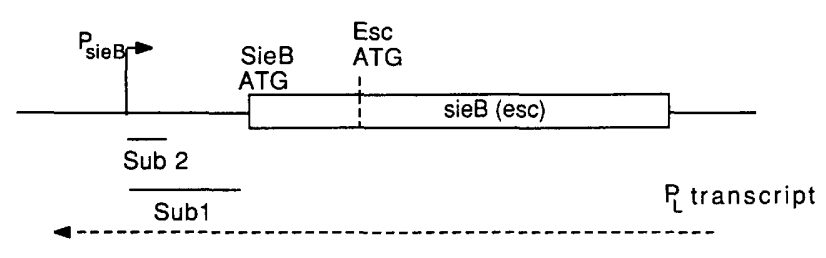

B

$$
\begin{array}{ll}
\text { Wild-type } & +1 \\
\text { Substitution } 1 & \text { GGGGAUACAGAGAGUAAAAAGAGAAUCGCCGAUG } \\
\text { Substitution } 2 & \text { GGGGAUGUC }
\end{array}
$$

Figure 3. $(A)$ The sieB/esc gene is shown, and the antisense $p_{\mathrm{L}}$ transcript is indicated as a broken arrow below. (Subl and Sub2) Substitutions 1 and 2 , respectively. $(B)$ The untranslated sequence of $\mathrm{P} 22$ sie $B$ is shown; $(+1)$ The transcription start site of $s i e B$; the $s i e B$ initiation codon is underlined. Shown below the wild-type sequence are the changes present in the two substitutions. 
tested on cells expressing sub2 sieB, and the results are presented in Table 1. As expected, P22 strains bearing amber mutations upstream of the esc initiation codon, am4, am14, and am22, plate as efficiently as does wildtype P22. P22 bearing mutations in esc, am29 and aml15, however, plate inefficiently. The plating behavior of P22 bearing another mutation, $\mathrm{P}_{\text {sieB-10 }}$, was also tested. This mutation alters the -10 hexamer of the $\operatorname{sie} B$ promoter, thus preventing synthesis of $S i e B$ mRNA (Ranade and Poteete 1993). P22 $P_{\text {sieB-10 }}$ plates efficiently on cells expressing wild-type $\operatorname{sie} B$, suggesting that the $P_{\text {sieB-10 }}$ mutation has no effect on the antisense effector. On cells expressing sub2 sieB, however, the mutant plates with low efficiency. This latter result indicates that Esc is synthesized from the same transcript as SieB.

One might expect that mutations that restore the ability of the antisense effector RNA to base-pair with the target sub2 sieB mRNA should restore the ability of P22 escam115 to plate efficiently on cells expressing sub2 $\operatorname{sie} B$. To test this possibility, substitution 2 was combined with sieB/escaml15 on a plasmid and then introduced into P22 by homologous recombination. As expected, this phage plates inefficiently on cells expressing wild-type sieB, but it also grows poorly on cells expressing sub2 sieB (see Table 1). P22 sieB/escam115 bearing the larger substitution 1 also plates inefficiently on both cell types. On a SieB ${ }^{-}$cell, however, both phages plate with high efficiency. These results suggest that substitution 2 wrecks the ability of the sense/antisense pair to interact with each other even when it is borne by both effector and target RNAs. This hypothesis is discussed below.

\section{A P22 mutant that commits suicide}

Attempts to cross substitution 2 alone (in the absence of am115 in sieB/esc) into P22 failed; few progeny phage were recovered from the cross by plating on wild-type Salmonella, and among these the few tested were nonrecombinants (data not shown). In the light of results presented above - the inability of P22 sub2 sieB/escam 115 to grow on cells expressing sub2sieB-it seemed possible that substitution 2 by itself is lethal to P22, by preventing the phage from shutting off synthesis of its own SieB. We reasoned that substitution 2-carrying P22 might be prevented from committing SieB-induced suicide if the host were constitutive for the SieB inhibitor Esc. This is indeed the case. Substitution 2-carrying P22 (see Materials and methods for a description of how this was obtained) was tested for its plating efficiency on cells that do or do not express Esc. P22 sub2 plates 100fold more efficiently on Salmonella that expresses the SieB inhibitor, Esc, than on cells that are deficient in Esc. (The host was constitutive for Esc by virtue of harboring a derivative of pKR682 that carried the sieB/escam22 allele, and the control Esc ${ }^{-}$cells carried another derivative of pKR682 bearing the sieB/escam115 allele.) The lethality of substitution 2 is attributed solely to SieB made by the infecting phage because $\mathrm{P} 22$ bearing substi- tution 2 in combination with the sieB/escam 115 allele plates with high efficiency on $\mathrm{Esc}^{-}$and Esc ${ }^{+}$cells. This result suggests that wild-type P22 does not "SieB-exclude" itself during lytic growth because antisense RNA inhibits synthesis of SieB.

\section{sieB/esc antisense RNA inhibits synthesis of SieB but not Esc}

To test the effect of antisense RNA on the synthesis of $\mathrm{SieB}$ and Esc, plasmids expressing different lengths of sieB/esc antisense RNA were constructed; their relevant structures are indicated in Figure 4A. These plasmids are derivatives of pKR682, which carries the $s i e B / e s c$ region of P22 (but not $p_{\mathrm{L}}$, from which the antisense RNA is normally expressed). In addition, but at a different location, these plasmids have different fragments of the sieB/ esc region, which when transcribed from the heterologous lacUV5 promoter, produce different lengths of sieB/esc antisense RNAs /only these additional sequences are indicated as arrows under the genetic map in Fig. 4A). All three plasmids would direct synthesis of antisense RNA initiated at the EcoRV site in sieB/esc. Plasmid pKR687 would make a 732-nucleotide antisense RNA up to the HindIII site in $\mathrm{ral}_{\text {; }}$ plasmid pKR688 would direct synthesis of a $\sim 528$-nucleotide antisense RNA, and plasmid pKR689 would make a $\sim 448$ nucleotide antisense RNA. To ensure that antisense RNAs of the expected sizes are synthesized, a strong transcription terminator, $t_{\text {ant }}$, was placed after these fragments in all three plasmids.

The SieB phenotypes of these plasmids were determined (Fig. 4A), and expression of proteins from these plasmids was analyzed using maxicells (Fig. 4B). As can be seen in lane 2 , in the absence of any sieB/esc antisense RNA, both SieB and Esc are synthesized. The control plasmid-pBR322 with its tetracycline resistance-conferring gene deleted-directs synthesis of neither SieB nor Esc, as expected (Fig. 4B, lane 1). Plasmid pKR687 confers a SieB ${ }^{-}$phenotype and, in maxicells, directs synthesis of Esc but not SieB (Fig. 4B, lane 3), suggesting that this antisense RNA causes a switch in the translation of sieB/esc RNA, from directing synthesis of both SieB and Esc to Esc alone. Plasmids pKR688 and pKR689 confer a SieB ${ }^{+}$phenotype and, in maxicells, direct synthesis of SieB and Esc (Fig. 4B, lanes 4 and 5, respectively). The result with pKR688 suggests that sequences in the $p_{\mathrm{L}}$ transcript, which lie beyond the region of complementarity with $s i e B$ mRNA, are required for the antisense RNA to function. Interestingly, expressing antisense RNA complementary to Esc has little or no effect on its synthesis (c.f. lanes 2 and 5). Plasmid pKR688 seems to overproduce SieB and Esc; we do not understand the basis for this.

Esc, but not sas RNA, allows P22 to bypass SieBmediated exclusion by bacteriophage $\lambda$

Susskind and co-workers showed that coliphage $\lambda$ too 
Figure 4. (A) Plasmids used to analyze the effect of antisense RNA on expression of $s i e B$ and esc. The HindIII-MluI region present in the parent plasmid pKR682 is shown as a solid line below. Arrows indicate the extent of antisense RNAs that would be synthesized from the three plasmids. $\left(\mathrm{P}_{\text {lacuvs }}\right)$ The lacUV5 promoter; $\left(t_{\text {ant }}\right)$ a transcription terminator. The SieB phenotype conferred by these plasmids is also shown. $1+\mid$ Cells bearing that plasmid plate an Esc phage (L) 100- to 1000-fold less efficiently as compared with its plating efficiency on cells expressing an amber allele (am 115) of $s i e B$. $(-)$ The plating efficiency is $\sim 1$. (B) Autoradiograph of ${ }^{35} \mathrm{~S}$-labeled proteins expressed in maxicells and separated by SDS-PAGE. (Lane 1) pBR322 with its tetracycline resistance-conferring gene deleted; (lane 2) pKR682; (lane 3) pKR687; (lane 4) pKR688; (lane 5) pKR689. The positions of $\beta$-lactamase, SieB, and Esc are indicated at right.
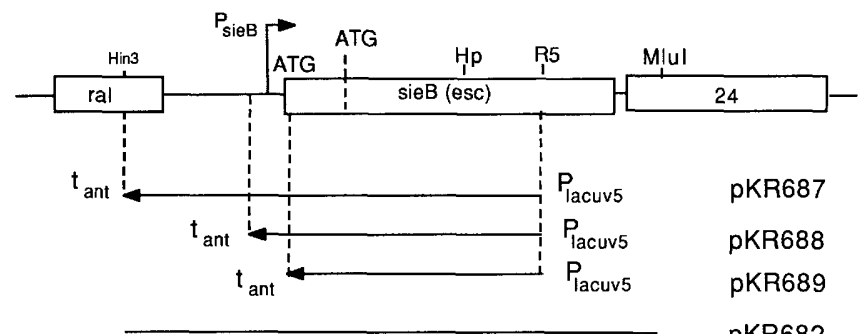

SieB phenotype

B

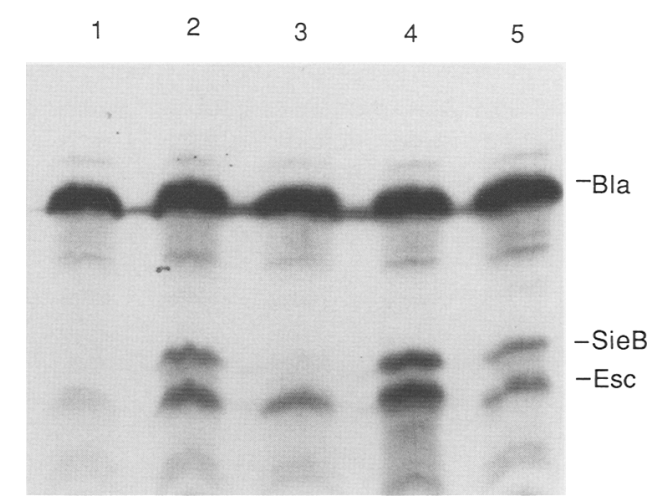

has a $\operatorname{sie} B$ gene, and this excludes the same Salmonella phages as $\mathrm{P} 22$ 's sieB, although there is little or no homology between the two genes. They also showed that P22 is insensitive to $\lambda$ SieB-mediated exclusion (Susskind and Botstein 1980). Below, we present evidence to suggest that Esc, but not sas RNA, allows P22 to circumvent $\lambda$ SieB-mediated exclusion.

The relevant region of the $\lambda$ genome is shown in Figure $5 \mathrm{~A}$. The structures of plasmids bearing the $s i e B$ gene are shown below. Plasmid pTP462 has the ea10-ral-sie$B$ (and a part of $N$ as well) region of $\lambda$; consequently in this plasmid, $\lambda$ sieB is expressed, most likely, from its own promoter. The region indicated by bold lines is homologous to that of $\mathrm{P} 22$; the untranslated regions of the $\operatorname{sie} B$ genes of the two phages are homologous but not identical (see Fig. 3B and 5B). Plasmid pTP482 has the sie $B$ gene under control of the heterologous lacUV5 promoter; the fusion is such that the entire untranslated region of $s i e B$ is replaced by unrelated sequence from the vector (see Fig. 5B). The plating behavior of some of the P22 mutants already described was tested on cells bearing these plasmids. The results are indicated in Table 2. As can be seen, wild-type P22 plates efficiently on Salmonella bearing either pTP462 or pTP482. P22 bearing an amber mutation in esc (sieB/escam115) or the sieB/ esc promoter mutation $\left(\mathrm{P}_{\text {sieB-1o }}\right)$, however, plates at least 100 -fold less efficiently on cells expressing $\lambda$ sie $B$ from its own promoter (pTP462) or from the lacUV5 promoter (pTP482). P22 bearing an amber mutation upstream of the esc initiation codon (am22), however, plates efficiently on both cell types. These results suggest that P22's Esc is able to neutralize the action of $\lambda$ SieB, but P22 sas RNA is unable to prevent synthesis of $\lambda$ SieB.

\section{Discussion}

In Figure 6 we present a molecular mechanism to explain P22's ability to circumvent SieB-mediated exclusion. In
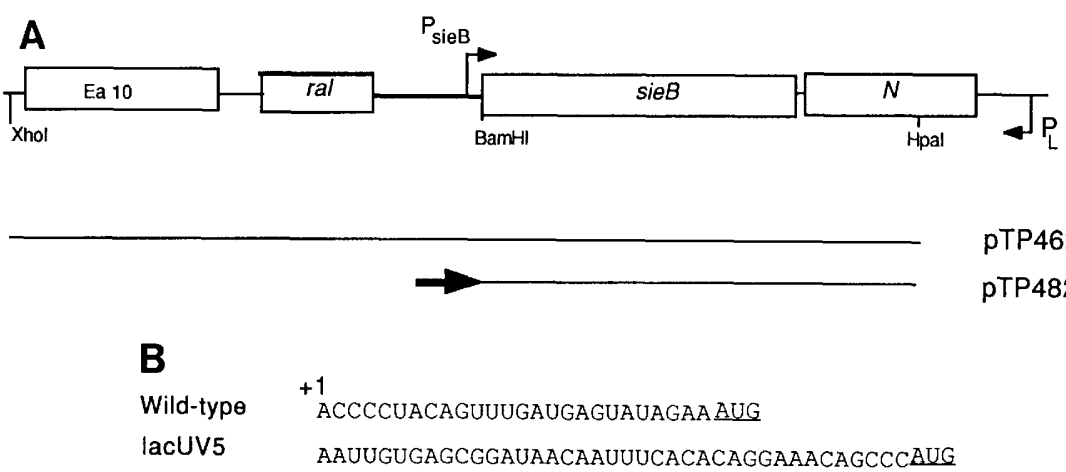

pTP462

pTP482

Figure 5. (A) Map of the $\lambda$ genome in the vicinity of the $s i e B$ gene. Sequences present in the $s i e B$-expressing plasmids constructed for these studies are shown below. $(B)$ The sequence of the untranslated region of $\lambda$ sie $B$ is indicated, and the sequence of the untranslated region in the lac fusion plasmid is shown below. 
Table 2. Esc phenotypes of P22 bearing different alleles of sieB/esc on cells expressing $\lambda$ sieB

\begin{tabular}{lcc}
\hline $\begin{array}{l}\text { sieB/esc } \\
\text { allele }\end{array}$ & \multicolumn{2}{c}{ sieB allele in host ${ }^{\mathrm{a}}$} \\
\cline { 2 - 3 } in P22 & pTP462 $\left(\mathrm{P}_{\text {sieB }}-\lambda\right.$ sieB $)$ & pTP482 $\left(\mathrm{P}_{\text {lac }}-\lambda\right.$ sieB $)$ \\
\hline Wild type & + & + \\
am22 & + & + \\
am115 & - & - \\
$\mathrm{P}_{\text {sieB-10 }}$ & - & - \\
\hline
\end{tabular}

This expeirment was performed essentially as described in Table 1, except that IPTG (at a final concentration of $1 \mathrm{mM}$ ) was added to lawns of cells bearing plasmid pTP482.

${ }^{a}$ A minus sign indicates that the phage plates 100 - to 1000 -fold less efficiently on a particular host as compared with its plating efficiency on cells bearing the am 115 allele of P22 sieB. A plus sign indicates that the plating efficiency is $\sim 1$.

a lysogen, the sieB/esc genes are expressed from a weak promoter just upstream of the $s i e B$ initiation codon; the strong leftward promoter $p_{\mathrm{L}}$ is repressed by the action of c2 repressor. The cell is phenotypically $\mathrm{SieB}^{+}$at this ratio of SieB (the exclusion protein) to Esc (the inhibitor protein); the prophage does not exclude itself, presumably because the trigger that activates the lethal action of SieB is present only during the lytic phase. Upon superinfection by virulent $\mathrm{P} 22$, the situation changes dramatically. There is a burst of transcription from the two major promoters of the superinfecting phage, $p_{\mathrm{L}}$ and $p_{\mathrm{R}}$ and low-level transcription from the sieB/esc promoter as well. The region of the $p_{\mathrm{L}}$ transcript, which is antisense with respect to $s i e B /$ esc mRNA, is processed into a 105-nucleotide $\operatorname{sie} B$ antisense effector RNA, sas. sas RNA then binds sieB/esc mRNA /synthesized from the prophage and superinfecting phage) and causes a switch in translation-from directing synthesis of both SieB and Esc, sieB/esc mRNA now directs synthesis of only Esc. In essence, superinfecting P22 circumvents SieB-mediated exclusion by altering the ratio of SieB to Esc. This mechanism has redundancy built into it because functional amounts of Esc can be made by the prophage or the superinfecting phage.

Several lines of evidence support this model. Amber mutations in sieB/esc have no effect on the plating efficiency of P22 on cells expressing wild-type sieB (Table 1), presumably because these phages are proficient at making sas RNA. Similarly a mutation that would hinder base-pairing between sas RNA and the target sieB mRNA (substitution 1 in Fig. 3) has no effect on P22's ability to grow in a $\mathrm{SieB}^{+}$host because the phage can still make Esc. When superinfecting P22 can make neither sas RNA nor Esc (sub1 sieB/escam115 and sub2 sieB/escam115; Table 1), it is no longer able to grow in a host-expressing wild-type $\operatorname{sie} B$. Alternatively, if the target $s i e B$ mRNA is rendered unresponsive to the translational switch induced by sas RNA, superinfecting P22 depends on its own Esc to bypass SieB-mediated exclusion (P22 sieB/escam29 and am115; $P_{\text {sieB-10; }}$ Table 1). The switch induced by sas RNA is essential to vegeta- tively developing P22; substitution 2, which renders $\operatorname{sie} B$ mRNA unresponsive to its antisense partner, causes P22 to SieB-exclude itself upon infection of a nonlysogen. When $s i e B$ is inactivated by an amber mutation (am115), however, substitution 2 is innocuous. Finally, artificial antisense RNAs inhibit the synthesis of SieB but not Esc (Fig. 4).

\section{sas RNA}

The status of the effector that causes the translational switch as an RNA molecule seems reasonably secure. (1) Mutations that render P22 susceptible to the lethal effect of SieB (in the absence of Esc) map to the untranslated region of $\operatorname{sie} B$ which is where many antisense RNAs act to regulate gene expression. (2) The $p_{\mathrm{L}}$ transcript is processed into a small 105-nucleotide molecule, and this molecule encompasses the region identified, by mutational studies, as being important for P22's ability to bypass SieB. The small size of sas is in harmony with other reported antisense RNA effectors, which are 50 110 nucleotides in length (Simons and Kleckner 1988).

A Uninfected lysogen
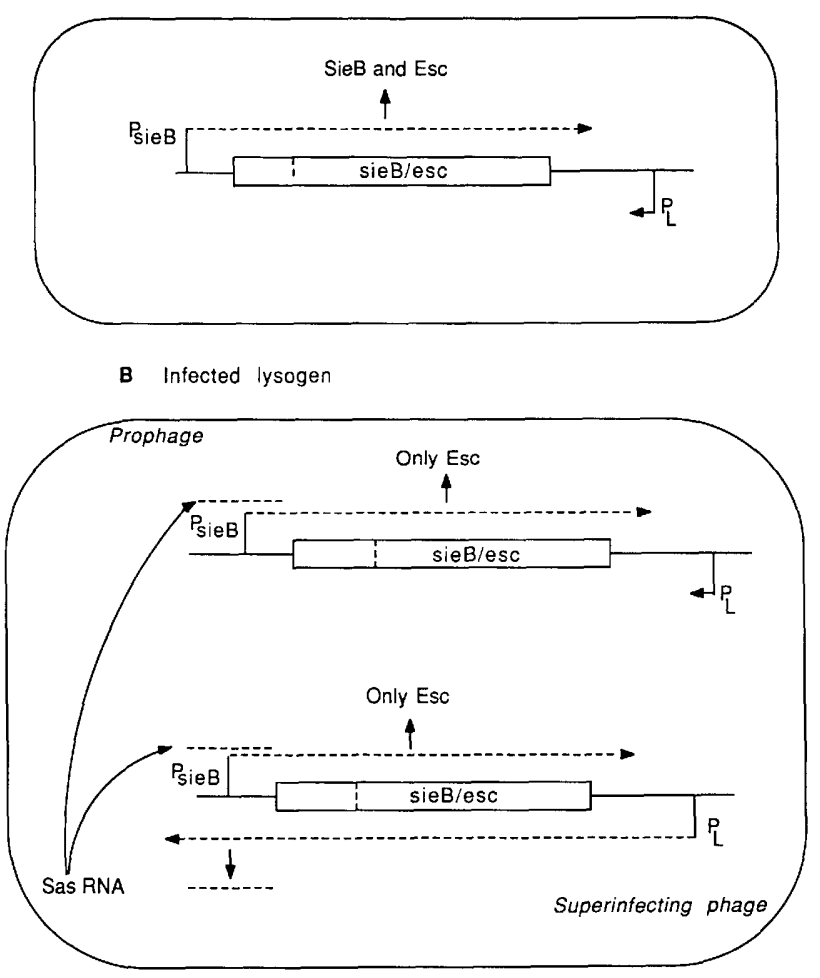

Figure 6. Molecular mechanism to explain P22's ability to bypass SieB-mediated exclusion. (A) In a lysogen, both SieB and Esc are synthesized from a transcript initiated at $\mathrm{P}_{\text {sieB }} p_{\mathrm{L}}$ is repressed by the phage repressor, $c 2$. $(B)$ In an infected lysogen, $\mathrm{P}_{\text {sieB }}$ and $p_{\mathrm{L}}$ of the superinfecting phage are transcribed. The $p_{\mathrm{L}}$ transcript is processed into sas RNA, which then acts on the target sieB/esc mRNA to cause a translational switch, thus allowing synthesis of only Esc. Broken arrows indicate transcripts. 
(3) There is no likely translation initiation site in sas RNA. Moreover, an amber mutation in the only substantive leftward open reading frame in this region of the $p_{\mathbf{L}}$ operon has no phenotype (data not shown).

The genetic approach to showing definitively that base-pairing interactions between two RNA molecules are important for the system in question is to isolate mutations in one that are compensated by mutations, which restore base-pairing, in the other. We have not yet shown this to be true of $s a s$ and $s i e B$ RNAs. Even when substitution 2 is present in both $\operatorname{sie} B$ mRNA and sas RNA, the sense and antisense RNAs are unable to interact with each other, making P22 susceptible to SieBmediated exclusion. This could be attributable to at least two reasons. First, substitution 2 is a relatively large mutation (9 nucleotides are changed), and this could affect the structure of the target and effector RNAs. Second, substitution 2 is very near the processing site in the $p_{\mathrm{L}}$ RNA, and it may affect the rate of processing or abolish processing completely. We note that most compensating mutations (those that restore sense and antisense pairing) that have been described are single-base changes ( $\mathrm{Si}$ mons and Kleckner 1988).

Several interesting questions about sas RNA and its action remain unanswered. We imagine that sas RNA acts by occluding the ribosome-binding site of $\operatorname{sie} B$ mRNA, but it is also possible that it acts by destabilizing this part of sieB/esc RNA. Such an effect has been documented in the case of $O O P$ antisense RNA and the hok/sok plasmid maintenance system (Krinke and Wulff 1990; Gerdes et al. 1992). Preliminary evidence, however, suggests that the stability of $\operatorname{sie} B$ mRNA is unaffected by sas RNA (data not shown). It is not clear whether the processing of $p_{\mathrm{L}}$ is absolutely essential for it to be an effective antisense RNA. The unprocessed form of $p_{\mathrm{L}}$ may be unable to interfere with the expression of sie $B$ or esc, perhaps because it cannot fold into the appropriate structure. Another point that deserves to be mentioned is that the region of $p_{\mathrm{L}}$ RNA $5^{\prime}$ to sas RNA is rapidly degraded; one can see only two protected species with the Hpa probe: full-length probe and sas RNA (see Fig. 1B). This observation suggests how P22 can synthesize Esc in the presence of the $p_{\mathrm{L}}$ transcript (because the $p_{\mathrm{L}}$ transcript is also antisense to esc mRNA) - the region of the $p_{\mathrm{L}}$ RNA that can base-pair with esc mRNA is rapidly degraded. The host enzymatic activity that is responsible for processing is unknown. The $c 4$ antisense RNA of bacteriophage $\mathrm{P} 1$ is also processed from a larger precursor; in that system, the tRNA processing activity, RNaseP, has been implicated (Citron and Schuster 1992).

\section{Relationship to other exclusion systems}

We have presented genetic evidence indicating that P22's Esc can circumvent the SieB-mediated exclusion system of $\lambda$ (Table 2). Although the untranslated regions of the $\operatorname{sie} B$ genes of the two phages are closely related, sas RNA acting alone evidently is not sufficient to allow P22 to bypass $\lambda$ SieB-mediated exclusion (Table 2). In contrast, sas RNA and Esc appear to make individually sufficient contributions to P22's ability to circumvent its own SieB (Table 1). We can envisage at least two reasons for this difference. (1) It may be that sas RNA can base-pair with $\lambda$ sieB mRNA but cannot cause a translational switch, perhaps because $\lambda$ sie $B$ does not encode an Esc-like inhibitor. According to this hypothesis, to disarm SieB, preventing its synthesis is not enough; SieB molecules already present in the cell must be neutralized, and this is accomplished by Esc. (2) It is possible that blocking SieB synthesis is sufficient, but P22 sas RNA might not bind $\lambda$ sieB mRNA because of the 17 base mismatch in the overlap regions of the two RNAs. If this is true, then it suggests why P22 has evolved Esc; it enables superinfecting P22 to bypass any exclusion system that functions through the same host macromolecule (or molecules) as does SieB. If the first possibility is correct, then it raises the question of how $\lambda$ is able to bypass its own SieB-mediated exclusion system. The answer may be that $\lambda$ is naturally insensitive to SieB-mediated exclusion (perhaps it lacks the ability to trigger SieB). A mutant of $\lambda$ with a large deletion in its $s i e B$ gene (and therefore its putative esc gene and sas RNA) plates efficiently on Escherichia coli expressing plasmid-borne $\lambda$ sieB (K. Ranade and A. Poteete, unpubl.).

The SieB/Esc system of exclusion that we have described resembles the RexA/RexB exclusion system elaborated by phage $\lambda$ (for review, see Court and Oppenheim 1983). This system is composed of two genes, rexA and $\operatorname{rex} B$, and their gene products abort the growth of certain mutants of phage T4; $\operatorname{Rex}^{+} \lambda$ lysogens of Salmonella also exclude P22. Parma et al. (1992) showed that when $\operatorname{rex} B$ is overexpressed in a $\operatorname{Rex}^{+} \lambda$ lysogen, it confers a $\mathrm{Rex}^{-}$phenotype, a result reminiscent of the effect of Esc on SieB-mediated exclusion. In that system, however, the biological relevance of this observation is not clear. They speculated that overexpression of $\operatorname{rex} B$ may be the mechanism by which an induced $\lambda$ prophage does not "Rex-exclude" itself.

\section{Materials and methods}

\section{Bacteria}

E. coli W3110 1acI $I^{Q}$ L8 (Brent and Ptashne 1981) was used for the propagation of plasmids, except for plasmids pKR687, pKR688, and pKR689, which were propagated in strain HB101 (Sambrook et al. 1989). Strain CSR603 recA1 uvrA6 (Sancar and Rupert 1978) was used for maxicell analysis. Salmonella typhimurium LT2 strains MS1868 (leuAam414 $\mathrm{r}^{-} \mathrm{m}^{+}$) and DB53 (cysA1348 hisC527 fels) were provided by M. Susskind (University of Southern California, Los Angeles).

\section{Plasmids}

Plasmid pTP546 was constructed by cutting pAS474 (Semerian et al. 1989) at the unique HindIII site followed by digestion with BAL31. The ends were filled in by the Klenow fragment of $E$. coli DNA polymerase I in the presence of all four deoxynucleotides and ligated in the presence of HindIII linkers. Plasmids pKR687, pKR688, and pKR689 were constructed as follows. The EcoRI-HindIII fragment from pKR682 (Ranade and Poteete 1993) was replaced by a $t_{a n t}$-bearing EcoRI-HindIII fragment from pTP550 (Semeriian et al. 1989); the resulting plasmid was called pKR683. The large ori-containing PstI-EcoRV frag- 
ments from plasmids pAS474, pTP546, and pTP520 (Ranade and Poteete 1993) were ligated with the $\mathrm{P}_{\text {lacuv5 }}$-bearing PstI-PvuII fragment from pTP30 (Berget et al. 1983); the resulting plasmids were called pKR684, pKR685, and pKR686, respectively. These plasmids were cut with HindIII, filled in, and digested with $P_{s t I}$ The resulting $s i e B / e s c$ antisense-expressing small fragments were ligated to the large ori-containing PstI-AfIII (filled-in) fragment from pKR683. To minimize intramolecular recombination, the new plasmids were propagated in strain $\mathrm{HB101}$. The recombinant plasmids are called pKR687, pKR688, and pKR689, respectively.

Mutant alleles of sieB/esc were constructed using site-directed mutagenesis as described (Kunkel et al. 1987; Ranade and Poteete 1993). Construction of the am 4 and $P_{\text {sieb-10 }}$ alleles of sieB/esc has been described (Ranade and Poteete 1993). The mutagenic oligonucleotides (mismatched nucleotides underlined) used to construct the other mutations were as follows: am14, 5'-CATTCCTTGCTAGAAAAAACG; am22, 5'-GCATATGAATCTACTGTTTAAG; am29, 5'-CAATACGATCTAGATGATTAG $\overline{\text {; }}$ am115, 5'-CGAATGCCAACTTACGCTCTTTC; substitution 1，5'-GTTCATCGGCGAAAGAGAAAAATGAGAGACATCCCCTGAATAGAGTTTATCCG-3'; and substitution 2, 5'-CTCTTTTTACTCTGACATCCCCTGAAATAGAGTTTATCC. (am refers to the amber mutation that was introduced into the sieB/esc gene, and the number that follows refers to that codon of $s i e B / e s c$ that was mutated to amber; substitutions 1 and 2 refer to the mutations that were introduced into the untranslated region of sieB/esc.) For crossing mutations into P22 (see below), a HindIII-EcoRV fragment, from an M13 clone carrying the mutation, was used to replace the wild-type HindIII-EcoRV fragment from pTP83 (Poteete 1982). For maxicell analysis, derivatives of pKR682 were constructed that carried the amber alleles of sieB/esc. This was accomplished by replacing the wild-type HindIII-EcoRV fragment from pKR682 with the mutation-bearing HindIII-EcoRV fragment from the corresponding M13 clone. Substitutions 1 and 2 were combined with am 115 as follows. Mutation-bearing HindIII-HpaI fragments were used to replace the corresponding wild-type fragment from a derivative of pKR682 carrying the aml15 allele of sieB/esc. HindIII-EcoRV fragments (bearing both mutations) from such derivatives of pKR682 were used to replace the corresponding fragment from pTP83 as outlined above.

To synthesize large amounts of riboprobe, 426-bp SaII-HpaI and 732-bp HindIII-EcoRV fragments from pTP650 (Ranade and Poteete 1993) and pKR682, respectively, were cloned into the polylinker of pGEM-4Z (Promega). The orientation of the inserts in the resulting plasmids is such that riboprobes complementary to $p_{\mathrm{L}}$ RNA can be made by digesting with the appropriate restriction endonuclease and transcribing with T7 RNA polymerase.

\section{Phage}

In some of the experiments, $\mathrm{L}$ was used as the control Esc ${ }^{-}$ phage (Susskind et al. 1974). Mutant alleles of sieB/esc were introduced into virulent $\mathrm{P} 22$ by crossing mutation-bearing plasmids with $\mathrm{P} 22$ vir $3 \Delta 474$. This phage was constructed by crossing P22 $\Delta 474$ (Semeriian et al. 1989) with P22 vir3, selecting for virulence, and screening for the deletion. P22 vir $3 \Delta 474$ has a large deletion in the kil-ral region; because the phage lacks gene 17 , it is unable to grow on a fels lysogen (Susskind and Botstein 1978). Salmonella strain MS1868 was transformed with mutant derivatives of plasmid pTP83, and plasmid by phage crosses (using P22 vir3 $\Delta 474$ ) were performed as described (Semeriian et al. 1989). The lysates from the crosses were plated on Salmo- nella strain DB53 (a fels lysogen) to select for recombinants that had picked up gene 17 from the plasmid. A large proportion of these also pick up mutations in sieB/esc. Virulent progeny were identified by their ability to form plaques on a P22 sieA44 a1 sieB::Kn567 lysogen (Ranade and Poteete 1993). Virulent P22 carrying mutations in sieB/esc were identified by DNA sequencing, as described (Rennell et al. 1991). P22 vir3 sub2 was constructed as follows. A derivative of pTP83 bearing substitution 2 sieB was constructed and transformed into Salmonella strain MS1868. A plasmid by phage cross was performed. When the lysate from such a cross was plated on DB53 (to select for recombinants that had picked up gene 17), few progeny phage were recovered, and the few tested did not carry substitution 2 . Consequently, the lysate was then plated on DB53 that constitutively expressed the SieB inhibitor Esc by virtue of having a derivative of plasmid pKR682 that expressed an amber allele of sieB (am22). A number of virulent P22 were picked, and their plating behavior on cells that do or do not express Esc was tested. Some of these plated with high efficiency only on cells that expressed Esc, and some plated with high efficiency on both. We inferred that the former class had substitution 2, whereas the latter was wild type.

\section{Maxicells and RNase protection}

Maxicell analysis was performed as described (Silhavy et al. 1984). RNase protection was performed essentially as described (Ranade and Poteete 1993), except that 10-15 $\mu \mathrm{g}$ of RNA was used; RNase A was used at a final concentration of $40 \mu \mathrm{g} / \mathrm{ml}$ (instead of nuclease $\mathrm{P} 1$ ), and proteinase $\mathrm{K}$ digestion (final concentration, $300 \mu \mathrm{g} / \mathrm{ml}$, in the presence of $3 \%$ SDS) was used to degrade ribonucleases. Riboprobes were synthesized as described by the supplier of plasmid pGEM-4Z (Promega). Following synthesis, the riboprobes were purified by fractionating on a $5 \%$ acrylamide/8M urea gel. Riboprobes were eluted from the gel as described (Sambrook et al. 1989). RNA was isolated using the lysozyme freeze-thaw method as described previously (Belfort et al. 1990). Phage infections to determine the status of $p_{\mathrm{L}}$ RNA were performed as follows. Cells were grown in LB medium at $37^{\circ} \mathrm{C}$ to a density of $2 \times 10^{8}$ cells $/ \mathrm{ml}$. The cells were then infected with P22 vir3 at a m.o.i. of 5 . Phage were allowed to adsorb at room temperature for $5 \mathrm{~min}$, and the infected cultures were aerated at $37^{\circ} \mathrm{C}$. Approximately 10, 20, and $30 \mathrm{~min}$ after infection, $30 \mathrm{ml}$ of culture was withdrawn and treated as described (Belfort et al. 1990). Just before infection, $30 \mathrm{ml}$ of culture was withdrawn as the uninfected control.

\section{Acknowledgments}

We thank Dale Rennell, Mimi Susskind, and Stuart Peltz for helpful discussions. This research was supported by a grant from the National Institutes of Health, (AI 18234).

The publication costs of this article were defrayed in part by payment of page charges. This article must therefore be hereby marked "advertisement" in accordance with 18 USC section 1734 solely to indicate this fact.

\section{References}

Belfort, M., E. Ehrenman, and P.S. Chandry. 1990. Genetic and molecular analysis of RNA splicing in E. coli. Methods Enzymol. 181: 521-539.

Berget, P.B., A.R. Poteete, and R.T. Sauer. 1983. Control of phage $\mathrm{P} 22$ tail protein expression by transcription termination. J. Mol. Biol. 164: 561-572.

Brent, R. and M. Ptashne. 1981. Mechanism of action of the 
lexA gene product. Proc. Natl. Acad. Sci. 78: 4204-4208.

Citron, M. and H. Schuster. 1992. The $c 4$ repressor of bacteriophage Pl is a processed 77 base antisense RNA. Nucleic Acids Res. 20: 3085-3090.

Court, D. and A.B. Oppenheim. 1983. Phage lambda's accessory genes. In Lambda II ( ed. R. Hendrix, J. Roberts, F. Stahl, and R. Weisbergl, pp 251-271. Cold Spring Harbor Laboratory, Cold Spring Harbor, New York.

Gerdes, K., A. Nielsen, P. Thorsted, and E.G. Wagner. 1992. Mechanism of killer gene activation. Antisense RNA-dependent RNase III cleavage ensures rapid turnover of the stable Hok, SrnB and PndA effector messenger RNAs. J. Mol. Biol. 226: 637-649.

Isberg, R.R., A.L. Lazaar, and M. Syvanen. 1982. Regulation of Tn 5 by the right-repeat proteins: Control at the level of the transposition reaction? Cell 30: 883-892.

Johnson, R.C., J.C.P. Yin, and W. Reznikoff. 1982. Control of Tn 5 transposition in Escherichia coli is mediated by protein from the right repeat. Cell 30: 873-882.

Krinke, L. and D.L. Wulff. 1990. RNase III-dependent hydrolysis of $\lambda$ cII-O gene mRNA by $\lambda$ OOP antisense RNA. Genes $\&$ Dev. 4: 2223-2233.

Kunkel, T.A., J.D. Roberts, and R.A. Zakour. 1987. Rapid and efficient site-specific mutagenesis without phenotypic selection. Methods Enzymol. 154: 367-382.

Parma, D.H., M. Snyder, S. Sobolevski, M. Nawroz, E. Brody, and L. Gold. 1992. The Rex system of bacteriophage $\lambda$ : Tolerance and altruistic cell death. Genes \& Dev. 6: 497-510.

Poteete A. R. 1982. Location and sequence of the erf gene of phage P22. Virology 119: 422-429.

- 1988. Bacteriophage P22. In The bacteriophages 2 /ed. R. Calendar|, vol. 2, pp 647-682. Plenum Press, New York.

Ranade, K. and A.R. Poteete. 1993. Superinfection exclusion (sieB) genes of bacteriophage P22 and $\lambda$. J. Bacteriol. 175: (in press|.

Rennell, D., S.E. Bouvier, L.W. Hardy, and A.R. Poteete. 1991. Systematic mutation of bacteriophage T4 lysozyme. J. Mol. Biol. 222: 67-88.

Sambrook, J., E.F. Fritsch, and T. Maniatis. 1989. Molecular cloning: A laboratory manual, 2nd ed. Cold Spring Harbor Laboratory Press, Cold Spring Harbor, New York.

Sancar, A. and C.S. Rupert. 1978. Determination of plasmid molecular weights from ultraviolet sensitivities. Nature 272: 471-472.

Schagger, H. and G. von Jagow. 1987. Tricine-sodium dodecyl sulfate-polyacrylamide gel electrophoresis for the separation of proteins in the range from 1 to $100 \mathrm{kDa}$. Anal. Biochem. 166: 368-379.

Semeriian, A.V., D.C. Malloy, and A.R. Poteete. 1989. Genetic structure of the bacteriophage P22 $\mathrm{P}_{\mathrm{L}}$ operon. J. Mol. Biol. 207: 1-13.

Silhavy, T.J., M.L. Berman, and L.W. Enquist. 1984. Experiments with gene fusions. Cold Spring Harbor Laboratory, Cold Spring Harbor, New York.

Simons, R.W. and N. Kleckner. 1988. Biological regulation by antisense RNA in prokaryotes. Annu. Rev. Genet. 22: 567600.

Susskind, M.M. and D. Botstein. 1978. Molecular genetics of bacteriophage P22. Microbiol. Rev. 42: 385-413.

- 1980. Superinfection exclusion by $\lambda$ prophage in lysogens of Salmonella typhimurium. Virology 100: 212-216.

Susskind, M.M., A. Wright, and D. Botstein. 1974. Superinfection exclusion by P22 prophage in lysogens of Salmonella typhimurium. IV. Genetics and physiology of sieB exclusion. Virology 62: 367-384.

Takayama, K.M. and M. Inouye. 1991. Antisense RNA. Crit.
Rev. Biochem. Mol. Biol. 25: 155-184.

Young, R. 1992. Bacteriophage lysis: Mechanism and regulation. Microbiol. Rev. 56: 430-481. 


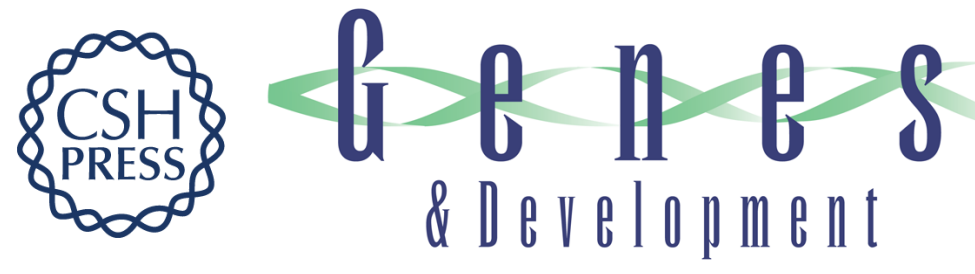

\section{A switch in translation mediated by an antisense RNA.}

K Ranade and A R Poteete

Genes Dev. 1993, 7:

Access the most recent version at doi:10.1101/gad.7.8.1498

References This article cites 21 articles, 5 of which can be accessed free at:

http://genesdev.cshlp.org/content/7/8/1498.full.html\#ref-list-1

License

Email Alerting Receive free email alerts when new articles cite this article - sign up in the box at the top Service right corner of the article or click here.

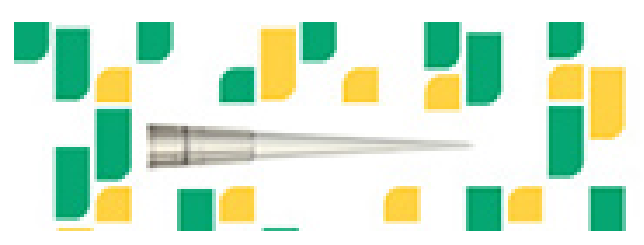

Focused on your science. 